\title{
0 metaprojeto na perspectiva da complexidade
}

Priscila Westphal Rodrigues é designer, empreendedora e mãe do Lucca inquieta por mudanças e apaixonada por DESIGN, decidiu colocar em prática os conhecimentos sobre Design, Gestão e Inovação na PRIW Design para apoiar empresas que desejam sair da zona de conforto, ousar, crescer e ter sucesso. Traz na bagagem experiências e formações para a realização de projetos de inovação, consultorias e treinamentos para equipes, como: Consultora, Professora e Palestrante de Inovação através do Design; Mestrado em Design Estratégico pela UNISINOS (2014); Representante brasileira em 2012 no treinamento para professores especialistas na área gráfica pela instituição alemã PrintPromotion; Professora de Design, Sustentabilidade e Produção Gráfica no Sistema S; Representante gaúcha no treinamento de formação de consultores de Design e Inovação pela Politécnica de Milano e pelo ITA - Instituto Tecnológico da Aeronáutica; Especialista em Informática na Educação pela PUC-RS (2010) e Bacharel em Design ULBRA (2007)

<priscila@priwdesign.com.br> ORCID: 0000-0002-2400-3180
Resumo $O$ presente artigo coloca em discussão o conceito de metaprojeto a partir da lente da teoria da complexidade. Para tanto, parte-se dos principais conceitos da teoria da complexidade com base em Morin (2006) e Capra (1996) e das diferentes vertentes teóricas sobre metaprojeto para embasar as análises. Por fim, propõe-se uma visão sobre o conceito de metaprojeto a partir da epistemologia da complexidade.

Palavras chave Pensamento complexo, Design estratégico, Metaprojeto.

\section{The metaproject in the perspective of complexity}

Abstract This paper discusses the concept of metaproject from the lens of complexity theory. For this reason, it is based on the main concepts of complexity theory based on Morin (2006) and Capra (1996) and the different theoretical aspects about to support the analysis. Finally, a view on the metaproject concept is proposed from the epistemology of complexity.

Keywords Complex thinking, Strategic design, Metaproject. 
Juliana Wolfarth é mestre em Design pela Unisinos, graduada em Administração de Empresas (Habiilitação em Gestão para Inovação e Liderança) pela Unisinos (Turma 2011/1). Atualmente trabalha na equipe de Projetos Estratégicos da Unisinos, mas teve inserção na Unidade Acadêmica de Pesquisa e Pós-Graduação junto à Coordenação de Marketing e Relacionamento, na área de Planejamento e Inteligência de Mercado, com inserções como docente em nível de pós-graduação lato senso. Também coordenou o MBA em Marketing e Vendas EAD entre 2016 e 2018. Tem experiência profissional na área de Gestão, Comunicação e Marketing e Pesquisa Mercadológica, Análise de Indicadores, Desenvolvimento de produtos, Inovação, com interesse em pesquisas nessas áreas e em outras áreas como experiência, comportamento e tomada de decisão do consumidor, Analytics e Big Data.<julianawolfarth@gmail.com>

Arlete Fante possui Medalha Cidade de Porto Alegre,2019 pelos relevantes serviços prestados à comunidade.

É Gestora dos Serviços de Saúde Mental e Comunitário da Associação Educadora São Carlos; Mestre em Design Estratégico UNISINOS, 2014; Mestre em Desenvolvimento Sustentável - Lanus- Argentina, 2006; Especialista em Gestão de Serviços de Saúde - UFRGS, 1996 e Especialista em Administração Hospitalar - PUC - 1993 Graduada em Filosofia - UPF,1984 $<$ fantearlete@gmail.com>

\section{Introdução}

Este artigo coloca em discussão o conceito de metaprojeto a partir da lente da teoria da complexidade. Metaprojeto é um conceito amplamente discutido no campo do design - mais especificamente do design estratégico, no entanto, percebe-se que não há consenso entre os autores. Giaccardi (2005) destaca que o termo é vago e elusivo, e que a cada vez que a palavra metaprojeto é utilizada, causa ainda mais confusão do que a palavra design.

Alguns autores, como Celaschi (2007), Deserti (2007), Moraes (2010) e Franzato (2012) apresentam o metaprojeto como um modelo de intervenção possível ao design em um cenário cada vez mais complexo e cheio de inter-relações. Deste modo, assumem que o ambiente em que o design atua é complexo, mas não discutem sobre como operar sobre essa realidade complexa.

Nesse sentido, propõe-se que o conceito de metaprojeto seja discutido não somente ao aceitar uma realidade complexa, mas sim a partir da epistemologia da complexidade, de acordo com os conceitos de Morin e Capra.

Design estratégico e complexidade são temas que estão constantemente em contato. Zurlo (2010) associa as palavras "complexidade" e "design estratégico" como palavras-problema, e apresenta o design estratégico sob a perspectiva da complexidade.

Para o autor, o termo design estratégico significa um sistema aberto para diferentes posicionamentos, modelos interpretativos e prospecções disciplinares que interferem no desenvolvimento teórico e prático da área.

Zurlo complementa ainda que no design estratégico as competências derivam da mobilização transdisciplinar capaz de dar forma, utilidade, valor e sentido a um sistema produto- serviço. 0 designer, por sua vez, precisa articular conhecimentos e pessoas, dentro e fora da organização, para acessar e simular a realidade em que vai agir. Um agir mais estratégico - e menos operacional - que está na base do conceito do design estratégico (ZURLO, 2010). 0 metaprojeto é a ponte para esse percurso, que visa à compreensão e à construção de modelos simplificados da realidade, que serão posteriormente manipulados a fim de modificarem esta realidade (CELASCHI, 2010).

Em complemento, Bentz e Parode (2012) explicam que, epistemologicamente, o design estratégico se inscreve na complexidade na medida em que a aproximação pela compreensão do processo que estimula a composição de múltiplos pontos de vista, experimentações e observações levam o grupo, aos poucos, a uma síntese interpretativa dos fatos numa dinâmica que vai do caos à ordem, construindo modelos simbólicos de representação da realidade.

Para a discussão que está sendo proposta, além desta introdução, o artigo está estruturado em três partes. A primeira busca introduzir os principais conceitos da teoria da complexidade, com base em Morin (2006) e Capra (1996). A seção seguinte apresenta as diferentes vertentes teóricas sobre metaprojeto e discute como os autores interpretam a teoria da complexidade. Em seguida, é apresentada uma nova visão sobre metaprojeto a partir da epistemologia da complexidade. Por fim, são apresentadas as principais considerações e implicações deste estudo. 


\section{A Teoria da Complexidade}

A Teoria da Complexidade para Morin (2006), a palavra complexidade significa "uma palavra problema e não uma palavra solução" com alto poder semântico que liga o empírico, o lógico e o racional onde o pensamento é "capaz de tratar o real, de dialogar e negociar com ele".

Por isso, não pode ser reduzida ou limitada a uma palavra, ideia ou lei. Para Capra (1995, p. 50) a teoria da complexidade está ligada à capacidade perceptiva e cognitiva com uma "propriedade da mente em todos os níveis de complexidade". Para o autor (1995) estes níveis de complexidade são interligados e interdependentes e não podem ser separados porque o que "enxergamos depende do modo como olhamos".

Nestas perspectivas, a complexidade é como um tecido. Morin (2006, p. 20) complementa a ideia de que "a complexidade é efetivamente o tecido de acontecimentos, ações, interações, retroações, determinações, acasos que constituem o nosso mundo fenomenal". É neste jogo de relações que se encontram as dificuldades para enfrentar a confusão, os fenômenos, a incerteza e as contradições. A partir disso, o conhecimento pode ser civilizado. Capra (1995, p. 176) aponta que a ciência do futuro pode ser capaz de lidar com uma gama de fenômenos naturais de modo unificado e consistente para descrever diferentes níveis e aspectos da realidade. Quanto mais complexo o sistema, mais difícil se torna o estabelecimento de modelos, entretanto, sem estes não há como tentar controlar ou administrar a complexidade. Consequentemente, isto acaba provocando um "atordoamento social".

Para Morin (2006, p. 116), "ação é estratégia", e nela há "o reino concreto e vital da complexidade". Propõe-se aqui que o acaso e a perturbação da ação mencionada pelo autor pode atingir a inovação pelo design, já que necessita ser interpretado para a modificação de cenários como resultado do processo de evolução do conhecimento que amplia-se em diversas possibilidades para a ação, que luta contra o acaso e ao mesmo tempo apropria-se dele. Capra (1995, p. 50) aponta que o espaço-tempo é algo entrelaçado e não deve ser aceito desde o princípio, considerando que esta é uma noção chave de "eventos suaves" que permite a combinação e a interação de ideias para provocar perturbações. Aponta que esta noção é infinita e a acumulação resulta em uma localização aproximada que favorece a emersão dos objetos isolados.

Na complexidade, a incerteza é uma parte desse sistema, mas não é reduzida ao termo, porque é em sistema que encontra-se devidamente organizada de maneira semialeatória para o acaso. Por isso, a complexidade é ordem e desordem e deve considerar a complexidade lógica e a complexidade organizacional (MORIN, 2006). Para Capra (2005, p.52) um sistema vivo só pode ser perturbado e o próprio ambiente pode desencadear estas perturbações. Por isso, nenhum sistema vivo pode ser controlado.

Morin (2006, p. 91) propõe que a "relação ordem/desordem/organização surge quando se verifica empiricamente que fenômenos desordenados são necessários em certas condições, em certos casos, para a produção 
de fenômenos organizados, que contribuem para o aumento da ordem". o autor define como ordem a repetição, a constância e a invariância que ambas dependem de uma lei. Contrapõe definindo que a desordem é a irregularidade, imprevisibilidade e o aleatório. Critica ainda que "estamos condenados ao pensamento inseguro a um pensamento crivado de buracos um pensamento que não tem nenhum fundamento absoluto de certeza. Mas somos capazes de pensar nestas condições dramáticas" (MORIN, 2006, p. 101). Neste aspecto, Capra (2006, p. 84) afirma que o padrão de organização de um sistema vivo se dá pela configuração entre os componentes do sistema e a sua estruturação, como a incorporação material e um processo contínuo dessa incorporação. Para o autor (2006, p. 136), a valorização da vida e da auto-organização fortalece e capacita o indivíduo.

Para Capra (2005, p. 58), o uso da teoria da complexidade busca a construção de uma ciência da consciência que explora as experiências subjetivas e dinâmicas-não lineares. Para isso, o autor (2005, p. 58) propõe três maneiras de análises: no método da psicologia de introspecção, numa abordagem fenomenológica e por meio da prática de meditação. Acrescenta ainda, que a redução fenomenológica, no sentido filosófico significa "recondução, uma libertação da experiência subjetiva através de uma suspensão da formulação de juízos acerca do que está sendo percebido".

Para Bentz e Parode (2012), uma das características da teoria da complexidade é o fato de que o pensamento se organiza e se posiciona na perspectiva de um infinito, de uma processualidade, onde o aleatório ocupa seu lugar como probabilidade no sistema. Nessa concepção o sistema é aberto e autogerador de relações.

Para Morin (2006) e Capra (1995), as interações entre os indivíduos dependem da cultura, da linguagem e do conhecimento. Capra (2006, p. 86) reforça que a consciência reflexiva está ligada à linguagem e ao contexto social, na qual destaca a dimensão hermenêutica e simbólica. Deste processo, destaca-se que a criação de conceitos, ideias, imagens e símbolos estabelecidas pelos significados gerados por uma consciência reflexiva sobre os fenômenos sociais embasadas em quatro perspectivas - forma, matéria, processo e significado.

Morin (2006, p.111) considera a necessidade de um meta-ponto de vista, ressaltando que este "só é possível se o observador-conceptor se integra na observação e na concepção" e justifica que não é possível separar sujeito e objeto porque no pensamento complexo há a necessidade desta integração que pode ser exemplificada pela linguagem que constitui o objeto.

O pensamento complexo constrói seus lastros em teorias que contemplam o movimento, na perspectiva de um devir, e também na percepção da arbitragem, na definição de fronteiras do conhecimento. Complementado essa ideia, Bentz e Parode (2012) também pautam o fato de que o conhecimento é cumulativo e de que a aproximação que a ciência tem da verdade, inscreve-se na historicidade da tecnologia e das relações sociais.

Morin (2006, p. 26) situa o conhecimento em um nível transdisciplinar na qual torna possível a associação e a organização dos fenômenos. 
O autor $(2006$, p. 39) propõe ainda que a informação é um conceito problemático com lacunas e incertezas, mas também é um conceito elucidado e elucidativo que merece ser aprofundado e não rejeitado.

Neste ponto, relaciona-se Capra (2006, p.96), ao afirmar que "em virtude da nossa capacidade de projetar imagens mentais para o futuro, nós, quando agimos, temos a convicção - válida ou não - de que nossas ações são voluntárias, intencionais e voltadas para um determinado objetivo". Assim, para o autor (2006, p. 133) a novidade torna-se uma propriedade de sistemas abertos para a organização de novas ideias e conhecimentos, na qual destaca a importância para a construção de "uma cultura de aprendizado que encoraje o questionamento constante e compense a inovação".

\section{Metaprojeto e suas principais vertentes}

Uma vez revisitados os principais conceitos relacionados à teoria da complexidade, cabe nessa seção discutir as características do metaprojeto conforme as diferentes vertentes que os autores propõem sobre o tema. Serão apresentadas como principais vertentes teóricas os seguintes autores: Giaccardi (2005), Celaschi (2007), Deserti (2007), Moraes (2010) e Franzato (2012). A escolha dos autores justifica-se por seguirem a linha da escola italiana que aborda o design sob a perspectiva estratégica.

Semanticamente, o significado principal do prefixo "meta" remete à mudança de lugar, ordem ou natureza. Historicamente, desde os anos 60, o termo metaprojeto - tradução de metadesign - vem sendo utilizado para evidenciar as possibilidades de "designing the design" ou "projeto do projeto". Nas últimas duas décadas, a ideia de metaprojeto tem sido abordada tanto como uma questão teórica, quanto como uma questão metodológica. Entretanto, destaca-se que como um conceito mantém-se isolado, sem produzir nem uma abordagem estabelecida, nem uma teoria coerente (GIACCARDI, 2005).

A referida autora explica que o desenvolvimento de um conceito de metaprojeto pode ser categorizado como um pensamento crítico e reflexivo sobre os limites e alcances do projeto, que busca lidar com a complexidade da interação humana mediada pela tecnologia. 0 metaprojeto pretende transformar essa complexidade em uma oportunidade para a geração de novas formas de criatividade e sociabilidade. Giaccardi (2005) aborda a multiplicidade de definições de metaprojeto, e estabelece as bases do conceito como uma cultura de design emergente.

Ao propor uma revisão sobre as origens do metaprojeto, Giaccardi (2005) percebe que alguns elementos são cruciais, tais como: foco sobre a concepção de estruturas e de processos em geral, em vez de objetos fixos e conteúdo; a necessidade de métodos e técnicas fluídas, ao invés de prescritivos; a atenção para ambientes que podem evoluir e a necessidade de configurações relacionais que permitem que os sistemas sejam com base em um processo mútuo e aberto para afetar e ser afetado.

Em seus estudos, Giaccardi (2005) revela que as teorias e aplicações sobre metaprojeto não são unidirecionais. De um lado, o metaprojeto tem 
sido considerado um modelo de design em rede, visando o refinamento do produto, personalização e customização em massa. De acordo com essa abordagem - com bases operacionais - o metaprojeto é considerado uma nova prática de design que é pouco questionadora. Por outro lado, a autora (2005) destaca que o metaprojeto tem sido concebido como uma cocriação: um esforço compartilhado de projeto que visa sustentar a emergência, a evolução e a adaptação. De acordo com esse desenvolvimento, os termos operacionais precisam ser colocados em uma prática mais reflexiva do design.

Em suma, a autora explica que o metaprojeto pode ser visto não somente como uma abordagem de design que informa uma metodologia específica para o desenvolvimento do projeto, mas também como uma forma de estratégia cultural que informa e integra diferentes domínios. Ao invés de um novo modelo de design, o metaprojeto representa um modo construtivo de design: um aprimoramento do processo criativo na convergência de "arte" e "ciência". A visão da autora aproxima-se da teoria da complexidade ao expor questões como emergência, evolução e adaptação, discordando de qualquer visão mais metodológica.

Em contraponto, Celaschi (2007) afirma que o metaprojeto representa uma passagem fundamental e indispensável para dirigir a inovação na direção adequada, e conceitua o metaprojeto como a programação do processo de pesquisa e projetação que desejamos utilizar, ou seja, como uma ação preliminar ao projeto. Para o autor (2007) a atividade que consideramos central no processo de inovação dos artefatos por meio do design é subdividida em dois processos distintos: aquele tradicionalmente conhecido como projeto e o nem tão reconhecido metaprojeto. Deste modo, o metaprojeto é visto como uma fase de pesquisa destinada a elaborar um conjunto de informações que baseiam o processo de inovação.

Celaschi (2007) explica que o processo de inovação é de difícil padronização; por isso propõe o metaprojeto como uma breve verificação de mercado, como um "projeto do projeto", ou seja, como um programa articulado e analítico, subdividido em fases, tempos e recursos econômicos e humanos necessários para cada fase que constituirá o "plano regulador geral" do processo de inovação. Por fim, o autor separa os conceitos de projeto e metaprojeto como se fossem processos distintos.

Por esta razão, percebe-se que Celaschi possui uma visão linear do processo de design ao conceituar metaprojeto como uma etapa do projeto. Sua leitura sobre metaprojeto impõe fases distintas e com temporalidades definidas.

Deserti (2007) apresenta uma abordagem complementar à Celaschi. Diferencia-se ao assimilar o percurso metaprojetual como um ambiente complexo, prevendo que o projeto surja, de um lado, da capacidade de analisar e interpretar os vínculos representados pelo contexto; e de outro lado, da capacidade de gerar oportunidades canalizando a criatividade dentro dos cenários e direções de inovação potenciais.

Nesse sentido, o autor traz, como objetivo didático um modelo que apresenta duas macroáreas do metaprojeto. A primeira envolve a obtenção de informações úteis para o projeto (pesquisa contextual) e a segunda 
corresponde à construção de diferentes direções e perspectivas projetuais (pesquisa blue-sky) onde ambas envolvem diferentes tipos de pesquisa e contribuem para a inovação. Assim, o autor entende que elas vivem uma relação dialética e aponta que o projeto se alimenta tanto de vínculos quanto de oportunidades, limites, impulsos pró-ativos, cálculos e faíscas criativas.

Deserti (2007) esclarece que não deseja sustentar uma abordagem metodológica. Ao contrário, a ideia é que na fase contemporânea seja oportuno dotar-se mais que de um método universal, mas de uma série de instrumentos, como uma espécie de "pack of tools" à disposição do projetista, que podem ser recombinados diante do contexto no qual opera e da necessidade específica que deve satisfazer. 0 autor, no entanto, também trata alguns desses momentos metaprojetuais como algo que antecede o projeto. Dessa forma, também possui uma visão linear, mesmo considerando a existência de um percurso mais complexo e de uma relação dialética entre as macroáreas.

Já Moraes (2010) apresenta novas nuances sobre o conceito ao afirmar que o metaprojeto é como um espaço de reflexão disciplinar e de elaboração dos conteúdos da cultura do projeto. Assim, o metaprojeto vai além do projeto, pois transcende o ato projetual. Seu trabalho nasce da necessidade de uma plataforma de conhecimentos que sustente e oriente o projeto em um cenário fluido e em constante mutação. Neste sentido, o metaprojeto possui um caráter holístico e abrangente.

Pelo seu caráter dinâmico, o metaprojeto desponta como um modelo que considera todas as hipóteses possíveis dentro das potencialidades do processo de design. Destaca-se que este processo não produz output, ou seja, um modelo projetual único e de soluções técnicas preestabelecidas. Para o autor (2010) o metaprojeto é uma alternativa posta ao design, que contrapõe os limites da metodologia projetual tradicional, ao se posicionar como uma etapa de reflexão e de suporte ao desenvolvimento do projeto em um cenário em constante mutação e complexidade.

Pontua-se Moraes (2010) ao apontar para a necessidade de repensar a metodologia de design. $O$ autor (2010) não propõe uma nova metodologia porque considera que o metaprojeto revela-se de forma ampla, como uma plataforma de conhecimentos. Para isso, utiliza como sinônimo de plataforma de conhecimentos o termo "pack of tools" ou pacote de ferramentas.

Moraes (2010) destaca ainda que o metaprojeto produz um articulado e complexo sistema de conhecimentos prévios que serve de guia durante o processo projetual. $O$ autor chama o metaprojeto de fase e ressalta que $o$ mesmo não vem antes ou depois do projeto, mas localiza-se em outro plano. Por isso, o autor salienta que o metaprojeto é aquele "que vai além do projeto, que transcende o projeto, que faz reflexão crítica e reflexiva sobre o próprio projeto" (MORAES, 2010, p.28).

As ideias de Moraes alargam o conceito de metaprojeto. Ao mesmo tempo que trata como uma fase, utiliza pack of tools e propõe que este pode localizar-se em outro plano que não o do projeto, articulado como sistema aberto e de plataformas de conhecimento. Tais afirmações deixam dúvidas em relação às bases teóricas do autor. 
No entanto, o que fica claro é que o autor assume o contexto de atuação do design como algo complexo. Em complemento, ao falar da processualidade do metaprojeto, Moraes afirma que não é exigida uma sequência lógica, única, linear e objetiva. Dessa forma, o autor faz uma ruptura na temporalidade, que é compreendida como um indício de utilização dos conceitos da teoria da complexidade.

Franzato e Celaschi (2012) apresentam outra visão, indicando que o metaprojeto é apropriado para o desenvolvimento de processos empresariais orientados para repensar radicalmente a atuação de uma organização e definir suas estratégias futuras tendo em vista a inovação.

Os autores (2012) complementam que metaprojeto pode ser visto como uma plataforma de conhecimentos e como um processo de reflexão contínua: "A abordagem metaprojetual prevê a evolução de uma reflexão acerca do projeto em desenvolvimento, paralela e para além dele, que fundamente e justifique o projeto em si, em relação ao contexto que o originou e em relação ao cenário para o qual é destinado" (FRANZATO e CELASCHI, 2012, p.2). Abordam ainda, o metaprojeto como uma atividade transdisciplinar embasada na pesquisa e tencionada para dentro do projeto ao longo das diversas fases do processo de design. 0 metaprojeto estimula uma reflexão posterior, que é incumbida para a conscientização dos diversos atores envolvidos no projeto para compreensão do seu significado.

Essa abordagem se aproxima da teoria da complexidade, uma vez que elimina a questão temporal. Além disso, para os autores, o processo ocorre de forma paralela e para além do projeto, ou seja, é possível acessar o metaprojeto a qualquer momento, não submetendo o trabalho a etapas rígidas e preestabelecidas. Neste ponto entende-se que a desordem pode implicar transformação que pode levar à realimentação no processo de design.

\section{O Metaprojeto a partir da Teoria da Complexidade}

Considera-se, para esta análise, os pressupostos da teoria da complexidade apresentados anteriormente. A complexidade, portanto, está no olhar e não no objeto isolado. Diante do exposto, propõe-se o metaprojeto como acesso e compreensão da realidade na qual as organizações estão inseridas e possibilitam o posicionamento do design como um eixo articulador de diversas disciplinas para a geração de conhecimento e aprendizado transdisciplinar. Tendo em vista que a geração de projetos inovadores pode possibilitar mudanças culturais radicais e impulsionar novas trajetórias de inovação, e não necessariamente a criação de projetos de novos produtos.

O olhar pela lente da complexidade reforça a utilização do prefixo meta: significa que está em outro nível. Ou seja, o prefixo meta implica transformação do significado de projeto, uma mudança de lugar ou de condição, um deslocamento. Existe a possibilidade de extrapolar os limites do design e retomar a projetação. $O$ metaprojeto não vem antes nem depois do projeto porque está em outro nível, no nível da reflexão crítica - metalinguistico.

O metaprojeto com a lente da complexidade prevê uma ruptura na temporalidade, uma desformatação da temporalidade. Tudo está lá e pode- 
-se acessá-la a qualquer momento. Portanto, não é necessário submeter o trabalho a etapas. Por este motivo, compreende-se que a desordem pode implicar em transformação. Entende-se que esta perspectiva envolve a captação dos sinais existentes no universo para impulsionar novas combinações e conexões em meio a desordem num sistema aberto. Considera-se também, que a compreensão destes sinais fazem parte do sistema para apropriação das oportunidades geradas pelas incertezas, pelo desconhecido, pelo nebuloso onde as reflexões sobre o processo de projeto tornam visíveis novas combinações e recombinações dos sinais existentes.

Estes sinais estabelecem uma luta contra o tempo por meio de ações diante do acaso e da perturbação em busca de soluções de problemas que não estão claramente definidos no início do processo de design. Por isso, compreende-se que estes sinais fazem parte de um sistema complexo que permanece interconectado e aberto para novas conexões. Aponta-se que a colisão, a combinação e o confronto destes sinais pelo design pode gerar novos efeitos de sentido e que seus significados podem estabelecer significados mais profundos aos destinatários dos projetos de design.

Reforça-se que a questão da temporalidade retoma um elemento de discordância entre os autores, uma vez que alguns indicam o metaprojeto como uma etapa, enquanto outros abordam como uma plataforma. Como etapa, o metaprojeto tem uma lógica que deve ser seguida. Já o olhar pela teoria da complexidade aponta que não há sequência lógica, mas sim a composição de múltiplos pontos de vista, experimentações e observações levam o grupo, aos poucos, a uma síntese interpretativa dos fatos numa dinâmica que vai do caos à ordem, construindo modelos simbólicos de representação da realidade, como indicaram Bentz e Parode (2008).

Neste sentido, trata-se de extrapolar os limites do design. Para isso, aponta-se que é fundamental importar conhecimentos para projetar, dialogar com outras disciplinas para, então, aplicar na projetação e conceber algo. O metaprojeto implica o deslocamento do contexto original, propondo um cenário para a combinação de novos sinais para o qual é destinado, ou seja, do entendimento do mercado, sociedade, empresa e consumidor, gerando soluções inovadoras com projetos conceituais, de produtos ou serviços.

Outra discussão importante que a teoria da complexidade esclarece é a questão da abordagem metodológica. 0 metaprojeto pode incluir uma abordagem metodológica. Alerta-se que este conceito é mais do que isso considerando que a partir da teoria da complexidade é impossível estabelecer um método perene, estanque e infalível.

Em relação aos elementos de incerteza, ordem e desordem, o metaprojeto possibilita ainda a auto-geração. Em uma visão mais prática, por exemplo, na processualidade de um workshop de design, busca-se diversas ideias para alterar o rumo inicial do projeto, com contribuições de diferentes áreas do conhecimento que possibilitam a construção de um conhecimento transdisciplinar com a recombinação dos elementos da realidade. Assim, considera- se que a desordem e a complexidade são características para a inovação. 


\section{Considerações Finais}

Por ora, este artigo apresentou uma discussão sobre o conceito de metaprojeto e suas diferentes vertentes teóricas. Com a análise e a discussão sobre o conceito, apontou-se que o metaprojeto é um conceito que leva à reflexão crítica sobre o processo de projeto, que pode ser aprofundado $\mathrm{e}$ reposicionar o modo como o designer percebe este processo, no qual induz ao rompimento de uma visão focada no objeto, como algo pontual e isolado a partir da aproximação da teoria da complexidade.

Entendeu-se que compreender o metaprojeto por este viés desacomoda o processo de design atual e instiga a construção de novas práticas que potencializem esta perspectiva, elevando o conhecimento dos envolvidos neste processo a uma reflexão no nível metalinguistico e não em etapas enrijecidas e preestabelecidas, como um passo-a-passo infalível. Deste modo, os designers são provocados para refletirem sobre o processo de design e para os fenômenos sociais para gerarem novas soluções.

Neste aspecto, percebeu-se que a abordagem do Design Estratégico tem se favorecido ao assumir o metaprojeto como algo intrínseco ao projeto e como um processo de reflexão crítica que questiona constantemente o problema de projeto ao longo do seu desenvolvimento. Assim, compreendeu-se que este é um ponto de partida inserido num sistema aberto que afeta e se permite afetar por diferentes intervenções disciplinares que auxilia na elevação do conhecimento dos envolvidos e que pode atingir a transdisciplinaridade.

Por esta razão, entendeu-se que o processo de design extrapola os limites atuais de projetação e da prática profissional diante dos altos níveis de incerteza, acaso, desordem e caos em ambientes complexos, sejam internos ou externos, onde os designers necessitam enfrentar e apropriar-se destes aspectos para o desenvolvimento de projetos de design que conduzam a uma nova realidade, a uma nova ordem, uma nova organização altamente dinâmica, integrada e interconectada para reconduzir as experiências humanas com significados mais profundos.

Entendeu-se a partir desta discussão sobre metaprojeto na perspectiva da teoria da complexidade que a inovação é algo que está intrínseco no processo de design e que a externalização dos resultado do processo de projeto são percebidos como projetos inovadores, mas que são difíceis de serem compreendidos porque exigem mais do que pesquisas, exigem a construção e o avanço do conhecimento transdisciplinar.

Compreendeu-se ainda, que em futuras pesquisas pode-se aprofundar este estudo buscando a perspectiva de metaprojeto a partir da complexidade no cotidiano das organizações e instituições que investem na viabilização de projetos inovadores tendo em vista a compreensão e a viabilização do processo metaprojetual. 


\section{Referências}

BENTZ; I. PARODE, F. Design estratégico e cultura pós-moderna. P\&D Design, 2012.

CAPRA, FRITJOF. Sabedoria Incomum. Editora Cultrix, São Paulo, 1995.

CAPRA, FRITJOF. As Conexões Ocultas. Ciência para uma vida sustentável. Editora Cultrix, São Paulo, 2005.

CAPRA, FRITJOF. A Teia da Vida. Uma nova compreensão científica dos sistemas vivos. Editora Cultrix, São Paulo, 2006.

CELASCHI, F. Dentro al progetto: Appuntidimerceologia contemporânea. In:

CELASCHI, F.; DESERTI, A. Design e innovazione: strumenti e pratiche per laricerzaapplicata. Roma:

Carocci Editore, 2007, p.15-56

CELASCHI, F. A Contribuição do Designer ao Design Process. IN: MORAES, D. Metaprojeto: o design do design. São Paulo. Ed: Blucher, 2010.

DESERTI, A. Intorno al progetto: concretizzarel'innovazione. In: CELASCHI, F.;

DESERTI, A. A. Design e innovazione: strumenti e pratiche per laricerzaapplicata. Roma: Carocci. Editore, 2007, p.15-56

GIACCARDI, E. Metadesign as an emergent Design Culture. LEONARDO, Vol. 38, No. 4, pp. 342- 349, 2005.

FRANZATO, C.; CELASCHI, F. Processo de metaprojeto para o desenvolvimento estratégico e a inovação das organizações. 10o Congresso Brasileiro de Pesquisa e Desenvolvimento em Design, São Luís (MA), 2012.

MORAES, Dijon de. Metaprojeto: o design do design. São Paulo: Blucher, 2010.

MORAES, Dijon de. Metaprojeto como modelo projetual. Strategic Design Research Journal, 3 (2): 62-68 maio-agosto 2010.

MORIN, Edgar. Introdução ao pensamento complexo. Porto Alegre: editora Sulina, 2006.

ZURLO, Francesco. Design Strategico. In: XXI Secolo, vol.IV, Glispazi e learti. Roma: Enciclopédia Treccani, 2010. 